\title{
The role of matrix metalloproteinases (MMPs) and their inhibitors (TIMPs) in the development of esophageal cancer
}

\author{
Magdalena Groblewska $^{1}$, Maria Siewko ${ }^{2}$, Barbara Mroczko ${ }^{1}$, Maciej Szmitkowski ${ }^{1}$ \\ ${ }^{1}$ Department of Biochemical Diagnostics, Medical University of Bialystok, Poland \\ ${ }^{2}$ Department of Laboratory Diagnostics, the Sniadecki Regional Hospital in Bialystok, Poland
}

\begin{abstract}
Esophageal cancer (EC) is one of the most aggressive malignant tumors of the gastrointestinal tract. There are two distinct histological types of EC: esophageal squamous cell carcinoma and adenocarcinoma of the esophagus. Etiologic factors and the patterns of incidence of both subtypes are different. Matrix metalloproteinases (MMPs) and their tissue inhibitors (TIMPs) play an important role in esophageal carcinogenesis. Gellatinases MMP-2 and MMP-9 are able to degrade collagen IV from basement membranes and extracellular matrix which is related to tumor progression, including invasion, metastasis, growth and angiogenesis. It has been shown that increased expression of MMPs plays a crucial role in the development of several human malignancies, including esophageal cancer. The activity of MMPs is regulated by their endogenous natural inhibitors (TIMPs). Among these, the roles of TIMP-1 and TIMP-2 in EC development, tumor progression and formation of metastases have been most extensively characterized and best recognized. (Folia Histochemica et Cytobiologica 2012, Vol. 50, No. 1, 12-19)
\end{abstract}

Key words: adenocarcinoma of the esophagus, esophageal squamous cell cancer, matrix metalloproteinases, tissue inhibitors of metalloproteinases

\section{Esophageal cancer - epidemiology and risk factors}

Esophageal cancer (EC) belongs to the most aggressive malignant tumors of the alimentary tract. The frequency of new cases of EC in Western Europe and the USA is still increasing [1, 2]. It is the eighth most frequent tumor disease and the sixth leading cause of cancer death worldwide [3]. It has been established that the rates of mortality and incidence of EC are quite similar — probably because of the relatively late stage of diagnosis and the rapid progression of the tumor $[4,5]$. The occurrence of this tumor increases with age. The highest incidence of EC is observed in the age group between 50

\footnotetext{
Correspondence address: M. Groblewska, Department of Biochemical Diagnostics, Medical University of Bialystok,

Waszyngtona Str. 15a, 15-269 Bialystok, Poland; tel.: + 488574687 09, fax: + 488574685 85;

e-mail: bialka@umwb.edu.pl
}

and 70 years. In addition, EC relates to gender and is diagnosed more frequently in males than in females, with an approximate ratio 3-5:1 [6].

EC is characterized by rapid development in most cases. The prognosis in esophageal cancer is generally poor, even though the tumor is surgically removed at its early, resectable stage. Five-year survival of patients with EC is less than 5\% [7]. Moreover, only 10-20\% of patients who undergo radical esophagectomy survive five years. In patients with an inoperable cancer, the median survival is estimated as 13-29 months [7].

There are two distinct histological types of EC: esophageal squamous cell carcinoma (ESCC) and adenocarcinoma of the esophagus (ACE); the etiologic factors and the patterns of their incidence are different [8]. The most frequent histological type is squamous cell carcinoma, although in last decades the worldwide proportion of adenocarcinomas has increased almost five-fold [8]. Moreover, in Western Europe and the USA, the percentage of ACE among all cases of EC reaches 50\% [1]. It has been shown that in the United States, the in- 
cidence of ESCC has decreased by about $30 \%$ in last 30 years, and the greatest decline was observed in black males [8]. On the other hand, the frequency of ACE has increased four-fold in the same period, with a nearly five-fold elevation among white males [8].

Moreover, the established risk factors for EC are different in each type of tumor. Dietary factors influence both types of EC, and a higher intake of fruit and vegetables is associated with a reduced incidence of tumor [8]. Increased body mass index (BMI) is strongly associated with ACE risk, whereas obesity or overweight shows no association, or an inverse relationship, with ESCC [8, 9]. Lower socioeconomic status, associated with malnutrition, insufficient vitamin intake, smoking, and alcohol abuse, significantly increases the incidence of ESCC $[8,10]$. Additionally, in case-control studies, the independent and synergistic effect of smoking and alcohol has been shown [1].

ACE is more frequent in white males from higher socioeconomic groups. In addition, gastroesophageal reflux disease is consistently associated with ACE [9]. Pathogenesis of this type of cancer leads from chronic reflux to esophagitis and metaplastic lesions in Barrett's esophagus (BE), which might result in the development of adenocarcinoma [11, 12].

Moreover, certain infectious agents, such as human papilloma virus (HPV), herpes simplex virus (HSV) and Epstein-Barr virus (EBV) might be risk factors for esophageal cancer $[13,14]$. The presence of HPV has been found in 20-70\% of EC patients [15].

Esophageal cancer is a very difficult malignancy to cure and still has a poor prognosis. Reasons include late diagnosis of the tumor, biological features of the tumor, and a lack of early symptoms. The main method of tumor recognition in the esophagus is endoscopic examination and histopathological assessment of material obtained during biopsy. Moreover, endoscopy allows the detection of premalignant lesions and the early stage of EC. Unfortunately, there are no suitable serum/plasma biomarkers of EC, which would allow for the detection of this malignancy and its screening, especially compared to other tumors of the gastrointestinal tract. Some tumor markers have been tested for their usefulness in primary diagnostics of EC patients, estimating prognosis, monitoring of therapy and early detection of tumor recurrence. Squamous cell cancer antigen (SCC-Ag) and carcinoembryonic antigen (CEA) are the tumor markers commonly used in the diagnostics of esophageal cancer, but their diagnostic sensitivity and specificity remain unsatisfactory $[16,17]$.

\section{Matrix metalloproteinases (MMPs)}

The development of malignant neoplasms is a long-term and multi-step process, which results in rapid growth and invasion of tumor cells into lymphatic and blood vessels [18]. The first step of tumor development and metastasis is the proteolysis of microvessel basement membranes and invasion of endothelium. The migration of tumor cells is associated with the degradation of the extracellular matrix (ECM) [19]. The ECM is a dynamic structure composed of various macromolecules such as collagen, fibronectin, laminin and proteoglycans of connective tissue. Their role is the regulation of cells functions and establishment of a specific microenvironment. Transformation of ECM is an essential factor for various physiological and pathological processes, tissue development and formation, proliferation and differentiation of cells, as well as invasion and metastasizing of neoplastic cells. Moreover, ECM remodeling is a regulator of stromal-epithelial interactions during carcinogenesis of malignant tumors [20,21].

The components of the extracellular matrix (collagen, elastin, and gelatin) are degraded by various proteolytic enzymes, including matrix metalloproteinases (MMPs). The MMP family includes at least 28 members, representing a large class of multi-domain, zinc-dependent endopeptidases. All MMPs share homologous amino acid (AA) sequences, with conserved specific domain structures, related to their substrate specificity [22]. The structure of most MMPs includes a propeptide of about $80 \mathrm{AA}$, a catalytic domain containing about $170 \mathrm{AA}$, followed by a linker peptide called the 'hinge region', of variable length, and a hemopexin domain with about 200 AA. Matrilysin 1 (MMP-7), matrilysin 2 (MMP-26) and MMP-23 are exceptions, because their molecules lack the linker peptide and the hemopexin domain. Moreover, MMP-23 has a unique C-terminal cysteine-rich domain and an immunoglobulin-like domain directly after the C-terminus of the catalytic domain.

The criterion for membership of the MMP family is the homology of MMP sequence with the catalytic domain of collagenase 1 (MMP-1). There are six main families of MMPs: collagenases (MMP-1, MMP-8 and MMP-13), gelatinases (MMP-2 and MMP-9), stromelysins (MMP-3, MMP-10 and MMP-11), matrilysins (MMP-7 and MMP-26), membrane-type MMPs (MT-MMPs: MMP-14, -15, -16, -17, -24 and -25), and other MMPs, which are not categorized in any of the previous groups (MMP-12, -19, -20, -21, -23, -27 and -28) (Table 1).

The MMP may act either as free, unbound secreted enzymes or as transmembrane proenzymes that require activation after their secretion. The members of the MMP family form a cascade and activate each other. Accelerated breakdown of ECM occurs in various pathological processes, including inflammation, chronic degenerative diseases and tumor invasion. The main roles of MMPs in pathology include tissue destruction, fibrosis or may be expressed as weakening of ECM. 
Table 1. Classification and functions of matrix metalloproteinases (MMPs)

\begin{tabular}{|c|c|c|}
\hline Group & Metalloproteinase & Substrates \\
\hline \multicolumn{3}{|l|}{ Matrilysins } \\
\hline $\begin{array}{l}\text { The smallest among MMPs, } \\
\text { lack of hemopexin domain }\end{array}$ & $\begin{array}{l}\text { MMP-7 (matrilysin, } \\
\text { metalloendopeptidase) }\end{array}$ & Collagen type IV, glycoproteins, gelatine \\
\hline \multicolumn{3}{|l|}{ Collagenases } \\
\hline $\begin{array}{l}\text { Contain hemopexin domain } \\
\text { and peptide linking with catalytic } \\
\text { domain }\end{array}$ & $\begin{array}{l}\text { MMP-1 (interstitial } \\
\text { collagenase; collagenase 1) } \\
\text { MMP-2, MMP-9, fibronectin } \\
\text { MMP-8 (neutrophil collagenase; } \\
\text { collagenase 2) } \\
\text { MMP-13 (collagenase 3) }\end{array}$ & $\begin{array}{l}\text { Collagen type I, II, III, V, VII, VIII, X, } \\
\text { gelatine, IL-1 } \beta \text {, MMP-2, MMP-9, fibronectin }\end{array}$ \\
\hline \multicolumn{3}{|l|}{ Stromelysins } \\
\hline Metalloproteinases of stroma & $\begin{array}{l}\text { MMP-3 (stromelysin 1) } \\
\text { MMP-10 (stromelysin 2) } \\
\text { MMP-11 (stromelysin 3) } \\
\text { MMP-18 (collagenase 4) }\end{array}$ & $\begin{array}{l}\text { Proteoglycanes, fibronectin, laminin, elastine, } \\
\text { gelatine, vitronectine, plasminogen, fibrinogen, } \\
\text { fibrine, collagen type III, IV, V, antithrombin III, } \\
\text { MMP-1, MMP-2, MMP-8, MMP-9, MMP-13 }\end{array}$ \\
\hline \multicolumn{3}{|l|}{ Gellatinases } \\
\hline $\begin{array}{l}\text { High substrate specificity } \\
\text { to denatured collagen and gelatine }\end{array}$ & $\begin{array}{l}\text { MMP-2 (gelatinase A; } \\
72 \text { KDa metalloproteinase) } \\
\text { MMP-9 (gelatinase B; } 92 \mathrm{KDa} \\
\text { metalloproteinase) }\end{array}$ & $\begin{array}{l}\text { Collagen type I, IV, V, VII, X, gelatine, elastine, } \\
\text { laminin }\end{array}$ \\
\hline \multicolumn{3}{|l|}{ Membane-type MMPs } \\
\hline (A) transmembrane-type MMPs & $\begin{array}{l}\text { MMP-14 (MT1-MMP) } \\
\text { MMP-15 (MT2-MMP) } \\
\text { MMP-16 (MT3-MMP) } \\
\text { MMP-24 (MT5-MMP) }\end{array}$ & $\begin{array}{l}\text { Collagen type I, II, III, gelatine, elastine, } \\
\text { laminin, fibronectin, fibrine, proMMP-2, - } 13\end{array}$ \\
\hline (B) GPI-anchored MMPs & $\begin{array}{l}\text { MMP-17 (MT4-MMP) } \\
\text { MMP-25 (MT6-MMP) }\end{array}$ & \\
\hline \multicolumn{3}{|l|}{ Others MMPs } \\
\hline $\begin{array}{l}\text { MMPs which are not categorized } \\
\text { in any of the previous groups }\end{array}$ & $\begin{array}{l}\text { MMP-11 (stromelysin) } \\
\text { MMP-12 (macrophage metalloelastase) } \\
\text { MMP-19 } \\
\text { MMP-20 (enamelysin) } \\
\text { MMP-23 } \\
\text { MMP-27 } \\
\text { MMP-28 (epilysin) }\end{array}$ & Amelagenine, agrecanes, elastine \\
\hline
\end{tabular}

For example, destruction of tissues is observed in cancer invasion and metastasis [22], rheumatoid arthritis and osteoarthritis [23, 24], formation of decubitus and various ulcers [25], periodontal disease, brain injury [26] and neuroinflammatory diseases [27]. Fibrosis of tissues is characteristic for liver cirrhosis, fibrotic lung disease, otosclerosis, atherosclerosis, and multiple sclerosis [28]. The weakening of ECM occurs in dilated cardiomyopathy, epidermolysis bullosa, aortic aneurysm [29] or restenotic lesions [30].

\section{Tissue inhibitors of matrix metalloproteinases (TIMPs)}

The expression of MMPs is regulated at the transcriptional level by cytokines and growth factors and its activity could be regulated by proenzyme activation after its secretion or inhibited by their endogenous natural inhibitors. The tissue inhibitors of matrix metalloproteinases (TIMPs) provide a negative control of MMPs activity. Four various inhibitors of metalloproteinases have been characterized so far, designated as TIMP-1, TIMP-2, TIMP-3, and TIMP-4. Among them, TIMP-1 and TIMP-2 have been characterized most extensively.

The TIMPs inhibit active MMPs by forming 1:1 stoichiometric non-covalent complexes with the endopeptidase [31]. TIMP-1 and TIMP-2 are capable of inhibiting the activities of all known MMPs except MT-MMPs, and play a key role in maintaining the balance between ECM deposition and degradation in different physiological processes. Moreover, TIMP-1 can also complex with the precursor of MMP-9 [32], whereas TIMP- 2 and 4 can bind to the zymogen form 
of MMP-2, a 92-kDa type IV procollagenase [33, 34]. TIMP-3 inhibits not only the activity of MPP-1, $-2,-3$, -9 and -13 [35], but also the activity of MT-MMPs as well as TNF-alpha converting enzyme. This inhibitor is the only member of the TIMP family which is found exclusively in the extracellular matrix (ECM). However, the role of TIMPs is not restricted to the inhibition of MMPs. They possess growth promoting activities for various cell types as well as having antiangiogenic properties and promoting apoptosis [36-38].

\section{The role of MMPs and TIMPs in esophageal cancer}

\section{MMP-9}

Matrix metalloproteinases, especially MMP-2 and MMP-9, as well as their inhibitors, TIMP-1 and TIMP-2, play an important role in tumor invasion and metastasis. The imbalance between MMPs and their inhibitors may facilitate tumor progression. The gellatinases MMP-2 and MMP-9 have been studied in this regard because of their specificity for breaking down the collagen of basement membranes [39]. It has been proved that these enzymes are involved in the development of many malignant neoplasms: gastric, colorectal, pancreatic and breast cancer [40-43].

High MMP-9 protein expression in tumor tissues of EC patients has been shown in several studies [4, 18, 44-47]. Percentages of MMP-9 positive immunostaining (diagnostic sensitivity) in esophageal cancer tissue reached $78 \%$ in the study by Murray et al. [44] and increased with tumor stage. The diagnostic sensitivity of MMP-9 immunostaining in the study of El-Shahat et al. was $100 \%$ in stage IV EC [4].

MMP-9 immunohistochemical expression in EC tissue correlated significantly with the depth of tumor invasion ( $\mathrm{T}$ factor), lymphatic vessel permeation, nodal metastases ( $\mathrm{M}$ factor) and differentiation grade $(4,19$, and 45). In addition, the study of Koyama et al. demonstrated strong MMP-9 gelatinolytic activity measured in situ within the tumor nests in EC tissues [48]. They also demonstrated significant correlation between vascular invasion and activation of MMP-9 [48]. This is in line with the study of El-Sahat et al., who revealed that tissue expression of MMP-9 in EC tumor samples significantly correlated with the presence of CD34 antigen (the biomarker of vascular endothelial cells and neoangiogenesis) [4]. Microvessel density in patients with highly positive staining for MMP-9 was higher than in those with negative or weak staining for MMP-9 [4], which suggests that the expression of MMP-9 possibly could offer additional information about the aggressiveness and activity of esophageal carcinoma lesions. Moreover, high expres- sion of MMP-9 in cancer tissue may be a negative prognostic factor of EC patients' survival [45].

The recent study of our research team has shown that the preoperative serum levels of MMP-9 in esophageal cancer patients were statistically higher than in healthy subjects, and correlated with clinical stage of disease as well as with tumor size [46] (Figure 1). The diagnostic sensitivity of serum MMP-9 measurement was higher $(70 \%)$ than for classical tumor markers (CEA - 17\% and SCC-Ag - 64\%) and increased in the combination of MMP-9 with SCC-Ag [46].

\section{MMP-2}

MMP-2 activity in ESCC tissue was significantly increased in comparison with normal esophageal mucosa [49]. Enhanced expression of MMP-2 protein in ESCC tissues suggests its association with esophageal tumorigenesis. Overexpression of MMP-2 in ESCC was found twice as often as in paired distal normal esophageal tissues [50]. Moreover, MMP-2 might act as a biomarker of ESCC invasion and lymph node metastasis in this type of tumor [50]. The overexpression of MMP-2 in ESCC tumor samples was significantly associated with cancer stage, depth of tumor invasion and presence of lymph node metastases [50]. Additionally, Koyama et al. have also demonstrated a significant correlation between lymph node metastasis, lymphatic vessels involvement, vascular invasion and activation of MMP-2 in ESCC tissue using gelatine zymography in situ [48].

The expression of MMP-2 might be significantly associated with the tumor invasion not only in ESCC cells, but also within normal esophageal tissue surrounding tumor nests. The immunohistochemical analysis of its expression in relation to clinicopathological features of esophageal cancer in the study of Ishibashi et al. revealed that the presence of MMP-2 within cancerous lesions was associated with invasion into lymphatic and blood vessels [51]. In contrast, expression of this enzyme within the normal esophageal tissue around cancerous lesions correlated with depth of tumor infiltration ( $\mathrm{T}$ factor) and stage of cancer [51]. MMP-2 immunostaining in normal tissue adjacent to tumor was also a significant prognostic factor of disease recurrence-free survival in patients with advanced stages of EC, whereas the presence of this enzyme within ESCC tumor tissue had no significant effect on patients' survival, regardless of cancer stage [51].

\section{Other MMPs}

Matrix metalloproteinases other than MMP-9 and MMP-2 might also play a significant role in EC carcinogenesis and tumor development. It has been sug- 

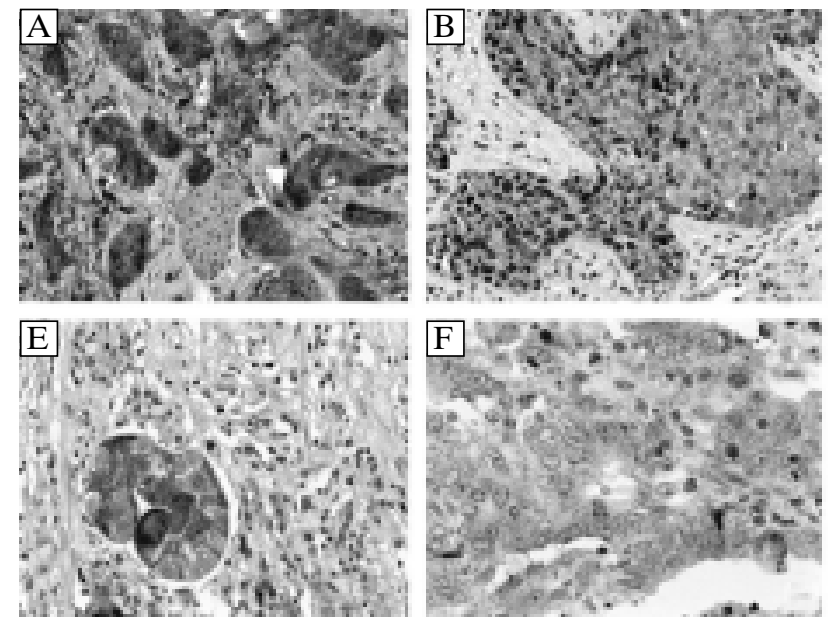
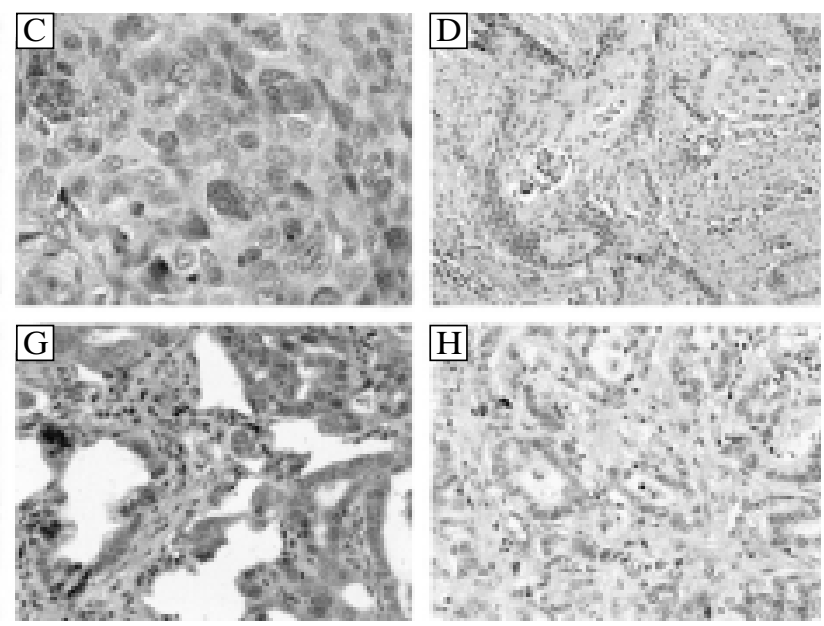

Figure 1. Typical staining result of MMP-9 in EC cancer cells from our previously published research paper [46]. A-D: Squamous cell carcinoma. A - intense expression in cancer cells ( 3 pts); B - moderate expression in cancer cells ( 2 pts); $\mathrm{C}$ - weak expression in cancer cells $(1 \mathrm{pt}) ; \mathrm{D}$ - no expression in cancer cells $(0 \mathrm{pt}) ; \mathbf{E}-\mathbf{H}$ : Adenocarcinoma. E — intense expression in cancer cells ( 3 pts); F - moderate expression in cancer cells ( 2 pts); $\mathrm{G}$ - weak expression in cancer cells $(1 \mathrm{pt}) ; \mathrm{H}-$ no expression in cancer cells $(0 \mathrm{pt})$

gested that MMP-1 was the preinvasive factor in Barrett's esophagus associated adenocarcinoma of the esophagus. Esophageal adenocarcinoma is related to gastroesophageal reflux and Barrett's esophagus, which is regarded as a precancerous lesion. Expression of MMP-1 was found in $95 \%$ of cases of ACE with $\mathrm{BE}$ and in $100 \%$ of cases of $\mathrm{ACE}$ without $\mathrm{BE}$, whereas no expression of MMP-13 was found in these specimens [52]. Moreover, increased MMP-1 expression was observed in tumor cells positive for $\mathrm{Ki}-67$ (the marker of cells' proliferation) whereas high MMP-1-mRNA levels were associated with lymph node metastases [52]. In addition, this enzyme might be a prognostic factor for EC patients' survival. The presence of MMP-1, as investigated by immunohistochemistry on formalin-fixed, wax-embedded sections of esophageal cancers, was associated with a particularly poor prognosis and was an independent, significant prognostic factor [44].

Mukherjee et al. measured protein expression levels of MMP-3 and MMP-10 using gelatin zymography in the tumor-associated stroma and tumor epithelium of ESCC [53]. A paired normal esophagus from a distant site was examined as a control. The authors found that MMP-3 and MMP-10 were strongly expressed in all examined tumors with little or no expression in the normal esophageal tissue [53].

In the study of Chen et al. the membrane-type 2 MMP (MT2-MMP) expression pattern in EC tissues was investigated and correlated to clinicopathological features of tumor, neoangiogenesis and postoperative prognoses [54]. They demonstrated that positive MT2-MMP immunoreactions were found in $85 \%$ of total tumor sections, whereas none or very weak
MT2-MMP staining occurred in normal esophageal tissues [54]. Moreover, MT2-MMP immunochemical staining intensity significantly correlated with angiogenesis in tumor tissue and tumor size [54].

\section{TIMPS}

TIMPs inhibit the activity of matrix metalloproteinases, and thus were considered to inhibit carcinoma invasion and metastasis. An inverse correlation between expression of TIMP-2 in ESCC cell sub-lines CE81T/VGH and invasive ability of neoplastic cells has been demonstrated [55]. The results indicate that TIMP-2 might have an inhibitory effect on esophageal tumor development and they are in line with the study of Sharma et al. who determined the prognostic significance of TIMP-1 and TIMP-2 immunostaining in esophageal squamous cell carcinoma in relation to tumor progression, invasion and metastasis [56].

In their study, the expression of TIMP-1 was observed in $66 \%$ of ESCC cases, whereas TIMP-2 was observed in $72 \%$, although TIMP-1(+)/TIMP-2(+) phenotype was inversely correlated with nodal invasiveness of the tumor [56]. Additionally, they analyzed the presence of both MMPs inhibitors in esophageal dysplastic tissues. An increased expression of TIMP-1 and TIMP- 2 was observed in $69 \%$ and $50 \%$ of esophageal dysplasias, respectively, which suggests that these alterations are rather early events in esophageal tumorigenesis [56]. In addition, it has been shown that MMP-11(+)/TIMP-2(-) phenotype might be a significant predictive factor for disease-free survival in ESCC patients [56]. The survival analysis in their study showed that patients with TIMP-2-negative carcino- 
Table 2. Matrix metalloproteinases (MMPs) and their tissue inhibitors (TIMPs) in esophageal cancer — summary

\begin{tabular}{|c|c|c|}
\hline Feature tested & MMPs & TIMPs \\
\hline $\begin{array}{l}\text { Expression in EC } \\
\text { cell lines }\end{array}$ & - & $\begin{array}{l}\text { TIMP-2: } \\
\quad \text { Chen } 2010 \text { [55] }\end{array}$ \\
\hline $\begin{array}{l}\text { Expression } \\
\text { in EC tissue }\end{array}$ & $\begin{array}{l}\text { MMP-9: } \\
\text { El-Shahat 2004 [4] } \\
\text { Samantaray 2004 [18] } \\
\text { Murray 1998 [44] } \\
\text { Tanioka 2003 [45] } \\
\text { Mroczko 2008 [46, 47] } \\
\text { MMP-2: } \\
\text { Augoff 2009 [4] } \\
\text { Li 2009 [50] } \\
\text { Ishibashi 2004 [51] } \\
\text { MMP-1: } \\
\text { Murray } 1998 \text { [44] } \\
\text { Grimm 2010 [52] } \\
\text { MMP-3: } \\
\text { Mukherjee 2010 [53] } \\
\text { MMP-10: } \\
\text { Mukherjee 2010 [53] } \\
\text { MT-2 MMP: } \\
\text { Chen 2010 [54] }\end{array}$ & $\begin{array}{l}\text { TIMP-1: } \\
\text { Sharma 2004 [56] } \\
\text { Vegh 2007 [57] } \\
\text { Salmela 2001 [59] } \\
\text { TIMP-2: } \\
\text { Sharma 2004 [56] } \\
\text { TIMP-3: } \\
\text { Salmela 2001 [59] } \\
\text { Miyazaki 2004 [60] }\end{array}$ \\
\hline $\begin{array}{l}\text { Clinicopathological } \\
\text { features of tumor }\end{array}$ & $\begin{array}{l}\text { MMP-9: } \\
\text { El-Shahat 2004 [4] } \\
\text { Gu 2005 [19] } \\
\text { Tanioka 2003 [45] } \\
\text { MMP-2: } \\
\text { Li 2009 [50] } \\
\text { Ishibashi 2004 [51] } \\
\text { MT-2 MMP: } \\
\text { Chen 2010 [54] }\end{array}$ & $\begin{array}{l}\text { TIMP-1: } \\
\text { Vegh 2007 [57] } \\
\text { Salmela 2001 [59] } \\
\text { TIMP-1: } \\
\text { Mori 2000 [58] } \\
\text { TIMP-3: } \\
\text { Salmela 2001 [59] } \\
\text { Miyazaki 2004 [60] }\end{array}$ \\
\hline \multirow[t]{2}{*}{$\begin{array}{l}\text { Enzymatic activity } \\
\text { mRNA }\end{array}$} & $\begin{array}{l}\text { MMP-9: } \\
\text { Koyama } 2000[48] \\
\text { MMP-2: } \\
\quad \text { Koyama } 2000 \text { [48] }\end{array}$ & - \\
\hline & $\begin{array}{l}\text { MMP-2: } \\
\quad \text { Ishibashi } 2004 \text { [51] }\end{array}$ & $\begin{array}{l}\text { TIMP-1: } \\
\quad \text { Mori } 2000 \text { [58] }\end{array}$ \\
\hline Serum/plasma levels & $\begin{array}{l}\text { MMP-9: } \\
\quad \text { Mroczko } 2008 \text { [46] }\end{array}$ & - \\
\hline $\begin{array}{l}\text { Prognostic factor of } \\
\text { overall or disease- } \\
\text {-free survival }\end{array}$ & $\begin{array}{l}\text { MMP-9: } \\
\text { Tanioka } 2003 \text { [45] } \\
\text { MMP-2: } \\
\text { Murray 1998 [44] } \\
\text { MT-2 MMP: } \\
\text { Chen 2010 [54] }\end{array}$ & $\begin{array}{l}\text { TIMP-1: } \\
\text { Mori 2000 [58] } \\
\text { TIMP-2: } \\
\text { Sharma } 2004 \text { [56] } \\
\text { TIMP-3: } \\
\quad \text { Miyazaki } 2004 \text { [60] }\end{array}$ \\
\hline
\end{tabular}

ma had a significantly shorter disease-free survival in comparison with TIMP-2-positive tumors [56]. Moreover, these observations are in line with the study of Vegh et al., who found that the expression of TIMP-1 in ACE samples from EC patients with more than three positive lymph nodes was significantly lower than in subjects without lymph node involvement [57].

On the other hand, the obtained data is in opposition to the study of Mori et al. [58], who compared expression of TIMP-1 mRNA in tumoral (T) and corresponding normal $(\mathrm{N})$ tissues of EC and evaluated the T:N ratio of TIMP-1 mRNA expression in each case [58]. A significantly higher frequency of lymphatic and vascular invasion, lymph node metastasis and advanced-stage disease, as well as poorer prognosis, was observed in high-expression cases $(\mathrm{T}: \mathrm{N}>2.0)$ than in the low-expression group
( $\mathrm{T}: \mathrm{N} \leq 2.0)$ [58]. Moreover, in multivariate analysis, TIMP-1 expression status was an independent factor for EC patients' prognosis [58]. They suggested that TIMP-1 expression correlated with tumor extension of esophageal carcinoma [58].

In the study of Salmela et al. it was demonstrated that in esophageal adenocarcinoma, TIMP-1 was expressed in $80 \%$ of cases, whereas TIMP-3 was expressed in 73\% of ACE tissue [59]. In contrast to TIMP-1, which was expressed in deeper areas of lesions, TIMP-3 was present throughout the cancer tissue, and in larger numbers of cells [59]. Moreover, the expression of TIMP-1 was observed particularly in aggressive tumors with poor differentiation, predominantly in fibroblast-like cells and in stromal cells surrounding glandular structures in $67 \%$ of lymph-node metastases, 
whereas expression of TIMP-3 was detected in $83 \%$ of samples of intestinal metaplasia and lymph node metastases [59]. These observations might reflect different biological roles of these two TIMPs; TIMP-1 is upregulated after the malignant cells protrude into deeper parts of the esophageal mucosa, whereas TIMP-3 is upregulated earlier in oncogenesis.

Miyazaki et al. analyzed the relationship between TIMP-3 reduction and clinicopathological factors in ESCC tumors [60]. They observed significant correlations between TIMP-3 presence in ESCC tumors and depth of tumor invasion, number of lymph node metastases, infiltrative growth pattern and cancer stage [60], which suggests that decreased expression of TIMP-3 is related to invasive activity and metastasis in this type of EC [60]. In addition, the survival rates of patients with TIMP-3(-) cancer were significantly lower than those of patients with TIMP-3(+) tumors, making the prognosis for patients with cancer that has lost TIMP-3 significantly less favorable than that for patients with cancer that has maintained TIMP-3 [60].

\section{Conclusions}

Esophageal cancer is one of the most aggressive malignant tumors of the upper gastrointestinal tract. There are two distinct types of this tumor: adenocarcinoma of the esophagus and esophageal squamous cell carcinoma, which differ in their etiology, risk factors, and incidence.

Matrix metalloproteinases and their tissue inhibitors are now recognized as important factors in the development of both types of esophageal cancer. MMPs, especially gellatinases A and B (MMP-2 and MMP-9, respectively), might facilitate tumor invasion and metastases. The effects of TIMPs on esophageal tumorigenesis are multifunctional and paradoxical they are considered as inhibitors of tumor development as well as growth factors (Table 2). The negative prognostic factors of EC patients' survival were: high expression of MMP-9 and MMP-1 in cancer cells, increase in MMP-2 immunoreactivity in normal tissue adjacent to tumor, as well as the increased ratio between the expression of TIMP-1 in tumoral tissue of EC and in corresponding normal cells. In contrast, the absence of the expression of TIMP- 2 or TIMP- 3 in cancer cells was an unfavorable prognostic factor in EC patients.

\section{References}

1. Crew KD, Neugut A. Epidemiology of upper gastrointestinal malignancies. Semin Oncol. 2004;31:450-464.

2. Pohn H, Welch HG. The role of overdiagnosis and reclassification in the marked increase of esophageal adenocarcinoma incidence. J Natl Cancer Inst. 2005;97:142-146.

3. Parkin MD, Bray F, Ferlay J, Pisani P. Global cancer statistics, 2002. CA Cancer J Clin. 2005;55:74-108.
4. El-Shahat M, Lotfy M, Fahmy L, Abouel-Nour MF, ElKenawy Ael-M. Prognostic value of microvessel density, matrix metalloproteinase- 9 and $\mathrm{p} 53$ protein expression in esophageal cancer. J Egypt Natl Cancer Inst. 2004;16:224-230.

5. Vallbohmer D, Lenz HJ. Predictive and prognostic molecular markers in outcome of esophageal cancer. Dis Esophagus. 2006;19:425-432.

6. Lundell LR. Etiology and risk factors for esophageal carcinoma. Dig Dis. 2010;28:641-644.

7. Coleman MP, Gatta G, Verdecchia A et al. Eurocare-3 summary: cancer survival in Europe at the end of the $20^{\text {th }}$ century. Ann Oncol. 2003;14:v128-149.

8. Holmes RS, Vaughan TL. Epidemiology and pathogenesis of esophageal cancer. Semin Radiat Oncol. 2007;17:2-9.

9. Mayne ST, Navarro SA. Diet, obesity and reflux in the etiology of adenocarcinomas of the esophagus and gastric cardia in humans. $J$ Nutr. 2002;132:3467S-3470S.

10. Lindblad M, Rodriquez LA, Lagergren J. Body mass, tobacco and alcohol and risk of esophageal, gastric cardia and gastric non-cardia adenocarcinoma among males and famales in nested case-control study. Cancer Causes Control. 2005;16:285-294.

11. Fass R, Sampliner RE. Barrett's oesophagus: optimal strategies for prevention and treatment. Drugs. 2003;63:555-564.

12. Hattori S, Muto M, Ohtsu A et al. EMR as salvage treatment for patients with locoregional failure of definitive chemoradiotherapy for esophageal cancer. Gastrointest Endosc. 2003;58:65-70.

13. Chang F, Syrjänen S, Shen Q et al. Evaluation of HPV, CMV, HSV and EBV in esophageal squamous cell carcinomas from a high-incidence area of China. Anticancer Res. 2000;20:3935-3940.

14. Lyronis ID, Baritaki S, Bizakis I, Tsardi M, Spandidos DA. Evaluation of the prevalence of human papillomavirus and Epstein-Barr virus in esophageal squamous cell carcinomas. Int J Biol Markers. 2005;20:5-10.

15. Yao PF, Li GC, Li J et al. Evidence of human papilloma virus infection and its epidemiology in esophageal squamous cell carcinoma. World J Gastroenterol. 2006;12:1352-1355.

16. Brockmann JG, St Nottberg H, Glodny B, Heinecke A, Senninger NJ. CYFRA 21-1 serum analysis in patients with esophageal cancer. Clin Cancer Res. 2000;6:4249-4252.

17. Shimada $\mathrm{H}$, Nabeya $Y$, Tagawa $M$ et al. Preoperative serum midkine concentration is a prognostic marker for esophageal squamous cell carcinoma. Cancer Sci. 2003;94:628-632.

18. Samantaray S, Sharma R, Chattopadhyaya TK, Gupta SD, Ralhan R. Increased expression of MMP-2 and MMP-9 in esophageal squamous cell carcinoma. J Cancer Res Clin Oncol. 2004;130:37-44.

19. Gu ZD, Li JY, Li M et al. Matrix metalloproteinases expression correlates with survival in patients with esophageal squamous cell carcinoma. Am J Gastroenterol. 2005;100:1835-1843.

20. Woessner JF Jr. Matrix metalloproteinases and their inhibitors in connective tissue remodeling. FASEB J. 1991;5:2145-2154.

21. Werb Z, Ashkenas J, MacAuley A, Wiesen JF. Extracellular matrix remodeling as a regulator of stromal-epithelial interactions during mammary gland development, involution and carcinogenesis. Braz J Med Biol Res. 1996;29:1087-1097.

22. Ii M, Yamamoto H, Adachi Y, Maruyama Y, Shinomura Y. Role of matrix metalloproteinase-7 (matrilysin) in human cancer invasion, apoptosis, growth, and angiogenesis. Exp Biol Med. 2006;231:20-27.

23. O'Byrne EM, Parker DT, Roberts ED et al. Oral administration of a matrix metalloproteinase inhibitor, CGS 27023A, protects the cartilage proteoglycan matrix in a partial meniscectomy model of osteoarthritis in rabbits. Inflamm Res. 1995;44:S117-118.

24. Cawston TE. Metalloproteinase inhibitors and the prevention of connective tissue breakdown. Pharmacol Ther. 1996;70:163-182.

25. Saarialho-Kere UK, Vaalamo M, Puolakkainen P, Airola K, Parks WC, Karjalainen-Lindsberg ML. Enhanced expression 
of matrilysin, collagenase, and stromelysin- 1 in gastrointestinal ulcers. Am J Pathol. 1996;148:519-526.

26. Rosenberg GA. Matrix metalloproteinases in brain injury. J Neurotrauma. 1995;12:833-842.

27. Chandler S, Coates R, Gearing A, Lury J, Wells G, Bone E. Matrix metalloproteinases degrade myelin basic protein. Neurosci Lett. 1995;201:223-226.

28. Woessner JF. The matrix metalloproteinase family. In: Parks WC, Mecham RP, eds. Matrix metalloproteinases. Academic Press, 1998:1-14.

29. Thompson RW, Parks WC. Role of matrix metalloproteinases in abdominal aortic aneurysms. Ann NY Acad Sci. 1996;800:157-174.

30. Strauss BH, Robinson R, Batchelor WB et al. In vivo collagen turnover following experimental balloon angioplasty injury and the role of matrix metalloproteinases. Circ Res. 1996;79:541-550.

31. Gomez DE, Alonso DF, Yoshiji H, Thorgeirsson UP. Tissue inhibitors of metalloproteinases: structure, regulation and biological functions. Eur J Cell Biol. 1997;74:111-122.

32. Wilhelm SM, Collier IE, Marmer BL, Eisen AZ, Grant GA, Goldberg GI. SV40-transformed human lung fibroblasts secrete a 92-kDa type IV collagenase which is identical to that secreted by normal human macrophages. J Biol Chem. 1989;264:17213-17221.

33. Goldberg GI, Marmer BL, Grant GA, Eisen AZ, Wilhelm S, He CS. Human 72-kilodalton type IV collagenase forms a complex with a tissue inhibitor of metalloproteases designated TIMP-2. Proc Natl Acad Sci USA. 1989;86:8207-8211.

34. Bigg HF, Shi YE, Liu YE, Steffensen B, Overall CM. Specific, high affinity binding of tissue inhibitor of metalloproteinases-4 (TIMP-4) to the COOH-terminal hemopexin-like domain of human gelatinase A. TIMP-4 binds progelatinase A and the $\mathrm{COOH}$-terminal domain in a similar manner to TIMP-2.J Biol Chem. 1997;272:15496-15500.

35. Apte SS, Olsen BR, Murphy G. The gene structure of tissue inhibitor of metalloproteinases (TIMP)-3 and its inhibitory activities define the distinct TIMP gene family. J Biol Chem. 1996;270:14313-14318.

36. Martin DC, Ruther U, Sanchez-Sweatman OH, Orr FW, Khokha R. Inhibition of SV40 T antigen-induced hepatocellular carcinoma in TIMP-1 transgenic mice. Oncogene. 1996;13:569-576

37. Anand-Apte B, Pepper MS, Voest E et al. Inhibition of angiogenesis by tissue inhibitor of metalloproteinase-3. Invest Ophthalmol Vis Sci. 1997;38:817-823.

38. Ahonen M, Baker AH, Kahari VM. Adenovirus-mediated gene delivery of tissue inhibitor of metalloproteinases-3 inhibits invasion and induces apoptosis in melanoma cells. Cancer Res. 1998;58:2310-2315.

39. Zeng ZS, Cohen AM, Guillem JG. Loss of basement membrane type IV collagen is associated with increased expression of metalloproteinases 2 and 9 (MMP-2 and MMP-9) during human colorectal tumorigenesis. Carcinogenesis. 1999;20:749-755.

40. Talvensaari-Mattila A, Paakko P, Turpeenniemi-Hujanen T. Matrix metalloproteinase-2 (MMP-2) is associated with survival in breast carcinoma. Br J Cancer. 2003;89:1270-1275.

41. Kubben FJ, Sier CF, Meijer MJ et al. Clinical impact of MMP and TIMP gene polymorphisms in gastric cancer. $\mathrm{Br} \mathrm{J} \mathrm{Can-}$ cer. 2006;95:744-751.

42. Giannopoulos G, Pavlakis K, Parasi A et al. The expression of matrix metalloproteinases- 2 and -9 and their tissue inhibitor 2 in pancreatic ductal and ampullary carcinoma and their relation to angiogenesis and clinicopathological parameters. Anticancer Res. 2008;28:1875-1881.

43. Murnane MJ, Cai J, Shuja S, McAneny D, Klepeis V, Willett JB. Active MMP-2 effectively identifies the presence of colorectal cancer. Int J Cancer. 2009;125:2893-2902.
44. Murray GI, Duncan ME, O’Neil P, McKay JA, Melvin WT, Fothergill JE. Matrix metalloproteinase-1 is associated with poor prognosis in oesophageal cancer. J Pathol. 1998;185:256-261.

45. Tanioka Y, Yoshida T, Yagawa T et al. Matrix metalloproteinase-7 and matrix metalloproteinase- 9 are associated with unfavourable prognosis in superficial oesophageal cancer. $\mathrm{Br}$ J Cancer. 2003;89:2116-2121.

46. Mroczko B, Kozłowski M, Groblewska M et al. The diagnostic value of the measurement of matrix metalloproteinase 9 (MMP-9), squamous cell cancer antigen (SCC) and carcinoembryonic antigen (CEA) in the sera of esophageal cancer patients. Clin Chim Acta. 2008;389:61-66.

47. Mroczko B, Kozłowski M, Groblewska M et al. Expression of matrix metalloproteinase-9 in the neoplastic and interstitial inflammatory infiltrate cells in the different histopathological types of esophageal cancer. Folia Histochem Cytobiol. 2008;46:471-478.

48. Koyama H, Iwata H, Kuwabara Y, Iwase H, Kobayashi S, Fujii Y. Gelatinolytic activity of matrix metalloproteinase-2 and -9 in oesophageal carcinoma: a study using in situ zymography. Eur J Cancer. 2000;36:2164-2170.

49. Augoff K, Grabowski K, Rabczynski J, Kolondra A, Tabola R, Sikorski AF. Expression of decorin in esophageal cancer in relation to the expression of three isoforms of transforming growth factor-beta (TGF-beta1, -beta2, and -beta3) and matrix metalloproteinase-2 activity. Cancer Invest. 2009;27:443$-452$.

50. Li Y, Ma J, Guo Q et al. Overexpression of MMP-2 and MMP-9 in esophageal squamous cell carcinoma. Dis Esophagus. 2009;22:664-667.

51. Ishibashi Y, Matsumoto T, Niwa M et al. CD147 and matrix metalloproteinase-2 protein expression as significant prognostic factors in esophageal squamous cell carcinoma. Cancer. 2004;101:1994-2000.

52. Grimm M, Lazariotou M, Kircher S et al. MMP-1 is a (pre) invasive factor in Barrett-associated esophageal adenocarcinomas and is associated with positive lymph node status. J Transl Med. 2010;8:99-110.

53. Mukherjee S, Roth MJ, Dawsey SM et al. Increased matrix metalloproteinase activation in esophageal squamous cell carcinoma. J Transl Med. 2010;8:91-97.

54. Chen L, Di D, Luo G et al. Immunochemical staining of MT2-MMP correlates positively to angiogenesis of human esophageal cancer. Anticancer Res. 2010;30:4363-4368.

55. Chen YK, Chang WS, Wu IC et al. Molecular characterization of invasive subpopulations from an esophageal squamous cell carcinoma cell line. Anticancer Res. 2010;30:727-736.

56. Sharma R, Chattopadhyay TK, Mathur M, Ralhan R. Prognostic significance of stromelysin-3 and tissue inhibitor of matrix metalloproteinase-2 in esophageal cancer. Oncology. 2004;3-4:300-309.

57. Vegh I, Santiuste AD, Colina F et al. Relationship between biomarker expression and allelic alteration in esophageal carcinoma. J Gastroenterol Hepatol. 2007;22:2303-2309.

58. Mori M, Mimori K, Sadanaga N et al. Prognostic impact of tissue inhibitor of matrix metalloproteinase-1 in esophageal carcinoma. Int J Cancer. 2000;88:575-578.

59. Salmela MT, Karjalainen-Lindsberg ML, Puolakkainen P, Saarialho-Kere U. Upregulation and differential expression of matrilysin (MMP-7) and metalloelastase (MMP-12) and their inhibitors TIMP-1 and TIMP-3 in Barrett's oesophageal adenocarcinoma. Br J Cancer. 2001;85:383-392.

60. Miyazaki T, Kato H, Nakajima M et al. An immunohistochemical study of TIMP-3 expression in oesophageal squamous cell carcinoma. Br J Cancer. 2004;91:1556-1560.

Submitted: 21 May, 2011

Accepted after reviews: 23 November, 2011 